\title{
THE INFLUENCE OF A SHRINKAGE REDUCING ADMIXTURE ON THE LONG-TERM DEVELOPMENT OF DYNAMIC PROPERTIES IN ALKALI-ACTIVATED SLAG
}

\author{
Martin Alexa $^{a}$, Dalibor KocÁB ${ }^{a, *}$, Barbara Kucharczyková $^{a}$, \\ JAN KOTRLA ${ }^{b}$
}

a Brno University of Technology, Faculty of Civil Engineering, Veveri 331/95, 602 00 Brno, Czech Republic

${ }^{b}$ Brno University of Technology, Faculty of Chemistry, Purkynova 464/118, 61200 Brno, Czech Republic

* corresponding author: dalibor.kocab@vutbr.cz

\begin{abstract}
The paper investigates the way a shrinkage-reducing admixture affects the long-term development of dynamic properties in mortars made with alkali-activated slag (AAS). Two AAS mortars were tested - one contained a shrinkage-reducing admixture, the other did not. The specimens (prisms of $40 \times 40 \times 160 \mathrm{~mm}$ ) were observed for changes in the dynamic modulus of elasticity at ages of 3 days through 2 years using the ultrasonic pulse velocity test and the resonance method. Even though the statistical analysis of the results gave no proof that the shrinkage-reducing admixture affected the final values, the development of the elastic modulus appeared to follow a very interesting trend which is completely different from trends commonly observed in cement-based composites.
\end{abstract}

KEYwORDS: Alkali-activated slag, dynamic modulus of elasticity, ultrasonic pulse velocity test, resonance method.

\section{INTRODUCTION}

Shrinkage, its reduction, or the means of mitigating its consequences are critical points in the development of all types of composite materials. The magnitude of shrinkage depends primarily on the composition of the material and its curing. The type of binder and the progress of hydration play a crucial part as well [1, 2. Alkali-activated binders have been investigated as alternatives to other concrete binders since the 1960s 3. Research shows that that the way alkaliactivated materials perform and behave depends on the raw aluminosilicate material, the activator, and the ratio of the two [4]. The alkali-activated slag composite discussed herein sometimes performs better than composites made with Portland cement (PC) specifically in such properties as durability, resistance to high temperatures, lower hydration heat, or a better interfacial transition zone [5. The biggest downsides of AAS composites are severe shrinkage and rapid setting (especially when the activator is water glass) [6] 8 .

Despite the effort of many investigations to describe the hydration process and mechanical properties of these composites [9 11], some questions pertaining to their behaviour still remain unanswered. Shrinkage by desiccation, which is far more severe in AAS than in PC [12, 13, results in internal tensile stresses which locally exceed the material's tensile strength and cause microcracks. This phenomenon can reduce both strength and elasticity. Using static tests to observe changes in the structure of the composite and how they may occur over a long period of time is rather time-consuming and requires a large num- ber of specimens. Even choosing the right static test is far from straightforward. This is why the structure of these materials is far better observed using dynamic methods based on mechanical wave propagation or forced vibration. These methods can determine the values of the dynamic modulus of elasticity (tensile/compressive, flexural, or shear), which are directly affected by structural changes inside the material. The authors of this paper have already published some of the measurement results (taken between the ages of 3 and 28 days) [14. However, experience showed that it is better to study the effect of shrinkage-reducing admixtures (SRA) over a longer time period. A minimum recommended time is 90 days.

\section{EXPERIMENT}

\subsection{Material AND SPECIMENS}

The experiment's main goal was to determine how a shrinkage-reducing admixture affects the long-term behaviour of AAS materials as regards the development of their dynamic modulus. Two mortars were tested; both made with granulated blast-furnace slag activated by water glass (sodium silicate). The slag was produced by KOTOUČ ŠTRAMBERK, spol. s r. o. and the water glass $\left(\mathrm{Na}_{2} \mathrm{O}+\mathrm{SiO}_{2}+\mathrm{H}_{2} \mathrm{O}\right)$ by Vodní sklo, a.s. The water glass was added so that $\mathrm{Na}_{2} \mathrm{O}$ would correspond to $10 \%$ of slag mass, resulting in a water-binder ratio of 0.42 (the calculation takes into account water contained in the water glass as well). The aggregate was normalized silica sand CEN of a $0-2 \mathrm{~mm}$ fraction. The weight of the sand corresponded to three times the weight of slag. The basic components and their ratios were identical in both mortars 
- they only differed in the shrinkage-reducing admixture (the commercially available Stachement AC600) - the first AAS contained no admixture and the other contained the SRA at $2 \%$ of slag weight. All AAS components were added to a mixer in the following order: sand, slag, and lastly water with water glass and shrinkage-reducing admixture (if required). The mortars were mixed for 5 minutes at $30 \mathrm{RPM}$.

Each of the mortars was made into 9 specimens with the nominal dimensions of $40 \times 40 \times 160 \mathrm{~mm}$. They were cast in high-strength plastic moulds and stored in a climate chamber with stable ambient conditions - temperature of $(21 \pm 2)^{\circ} \mathrm{C}$ and relative humidity of $(60 \pm 10) \%$ - where they were left to harden without cover or curing for 72 hours. This method was intentional so as to underline the influence of the SRA. After the specimens were removed from their moulds, they were left in the same conditions, still without curing, for the next 2 years.

\subsection{TEST METHODS}

The experiment focused on observing the Young's modulus $E$ and the shear modulus $G$. The measurements were made using two non-destructive methods - the ultrasonic pulse velocity test and the resonance method.

The basic principle of the former lies in the repeated sending of ultrasonic pulses through the material at very short intervals. A Pundit PL-200 with two $150 \mathrm{KHz}$ transducers was used to determine the ultrasonic wave transit time, measured longitudinally in three different positions (Fig. 17). The measured data were then used to calculate the ultrasonic wave velocity $v_{L}$, which is then used for determining the Young's modulus as follows:

$$
E_{c u}=\rho \cdot v_{L}^{2} \cdot \frac{(1+\mu) \cdot(1-2 \cdot \mu)}{1-\mu},
$$

where $E_{c u}$ is the dynamic Young's modulus in MPa, $\rho$ is bulk density in $\mathrm{kg} / \mathrm{m}^{3}, v_{L}$ is the ultrasonic pulse velocity in $\mathrm{km}$, and $\mu$ is the dynamic value of the Poisson's ratio.

The dynamic modulus of elasticity was also determined by the resonance method, which operates by introducing vibration to the specimen and detecting the natural frequencies. The specimens received a mechanical pulse delivered by an impact hammer (IH). The natural frequencies were then scanned using a Handyscope HS4 oscilloscope with acoustic emission sensors and software that uses a fast Fourier transform, see Fig. 1 b. The natural frequencies were then used to calculate the Young's modulus according to the following formula:

$$
E_{c r L}=4 \cdot L^{2} \cdot f_{L}^{2} \cdot \rho,
$$

where $E_{c r L}$ is the dynamic Young's modulus in MPa, $L$ is the specimen length in $\mathrm{m}, f_{L}$ is the measured natural frequency of longitudinal vibration in $\mathrm{kHz}$, and $\rho$ is bulk density in $\mathrm{kg} / \mathrm{m}^{3}$, or using the formula:

$$
E_{c r L}=0.0789 \cdot c_{1} \cdot L^{4} \cdot f_{f}^{2} \cdot \rho \cdot i^{-2},
$$

where $E_{c r f}$ is the dynamic Young's modulus in MPa, $c_{1}$ is the correction coefficient, $L$ is specimen length in $\mathrm{m}, f_{f}$ is the natural frequency of transverse vibration in $\mathrm{kHz}, \rho$ is bulk density in $\mathrm{kg} / \mathrm{m}^{3}$ and $i$ is the radius of gyration of the specimen's cross-section in $\mathrm{m}$.

Data obtained by the resonance method can also be used to calculate the shear modulus of elasticity using the formula:

$$
G_{c r}=4 \cdot k \cdot L^{2} \cdot f_{t}^{2} \cdot \rho,
$$

where $G_{c r}$ is the dynamic shear modulus of elasticity in $\mathrm{MPa}, k$ is a coefficient determined by the specimen's cross section, $L$ is specimen length in $\mathrm{m}, f_{t}$ is the measured natural frequency of torsional vibration in $\mathrm{kHz}$ and $\rho$ is bulk density in $\mathrm{kg} / \mathrm{m}^{3}$.

All nine specimens of each AAS mortar were tested for dynamic properties and bulk density at ages of $3,7,14$, and 28 days. At the age of 28 days, three specimens were tested for the static Young's modulus by compressive loading. The remaining six were later tested for dynamic properties at 90, 180, 365, and 730 days. The Pundit PL-200 used the same settings for every measurement - gain: $2 \times$ and voltage: $100 \mathrm{~V}$. The resonance method settings were also kept the same throughout the experiment. The dynamic Poisson's ratio used in formula (1) was obtained from the resonance method results.

\section{Results AND Discussion}

Fig. 2 through Fig. 5 show box plots of the measured dynamic parameters. In order to assess the influence of the shrinkage-reducing admixture, all the data sets, i.e. nine or six values of each property from every measurement date, were verified for normality on a significance level of 0.05 . In addition, the test results were statistically compared using a two-sample t-test on a significance level of 0.05 . The statistical tests were set up so as to assess the equality of the mean values of the test results. The comparison involved all results for all the ages contrasting AAS mortars without shrinkage-reducing admixture (AAS-1) with AAS mortars that did contain it (AAS-2). If the hypothesis is rejected, differences between the sets of results can be considered statistically significant.

Tab 1 shows the results of the statistical analysis. The data show that none of the mortars reaches values that would be statistically more significant in any of the property being tested at any time during the experiment. An influence of SRA on the dynamic moduli of elasticity in AAS mortars cannot be identified nor quantified in this case. Over the first 14 days of age, the two materials show no statistically significant difference in the values of the Young's modulus, but in other parameters the mortar with no SRA has slightly 

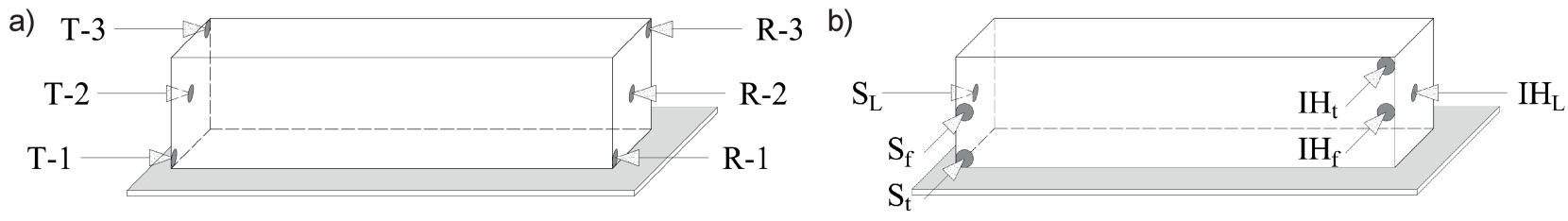

FIGURE 1. Measurement by the ultrasonic pulse velocity test ( $\mathrm{T}$ - transmitter, $\mathrm{R}$ - receiver); measurement by the resonance method ( $\mathrm{S}$ - acoustic emission sensor, IH - impact hammer).

\begin{tabular}{|c|c|c|c|c|}
\hline Age [days] & $E_{c u}$ & $E_{c r L}$ & $E_{c r f}$ & $G_{c r}$ \\
\hline 3 & AAS- $1 \approx$ AAS- 2 & AAS-1 > AAS-2 & AAS- $1>$ AAS- 2 & AAS-1 > AAS-2 \\
\hline 7 & $\mathrm{AAS}-1 \approx \mathrm{AAS}-2$ & AAS- $1>$ AAS- 2 & AAS- $1>$ AAS- 2 & AAS-1 > AAS-2 \\
\hline 14 & $\mathrm{AAS}-1 \approx \mathrm{AAS}-2$ & AAS- $1>$ AAS- 2 & AAS- $1>$ AAS- 2 & AAS-1 > AAS- 2 \\
\hline 28 & AAS-1 $<$ AAS- 2 & AAS-1 > AAS-2 & AAS- $1>$ AAS- 2 & AAS-1 > AAS-2 \\
\hline 90 & AAS-1 > AAS-2 & AAS-1 $>$ AAS-2 & AAS- $1>$ AAS- 2 & $\mathrm{AAS}-1 \approx \mathrm{AAS}-2$ \\
\hline 180 & AAS-1 $<$ AAS- 2 & AAS-1 $<$ AAS-2 & AAS- $1<$ AAS- 2 & AAS-1 $<$ AAS- 2 \\
\hline 365 & AAS-1 $<$ AAS- 2 & AAS- $1 \approx$ AAS- 2 & AAS- $1<$ AAS- 2 & AAS-1 $<$ AAS- 2 \\
\hline 730 & AAS-1 > AAS- 2 & AAS- $1>$ AAS- 2 & AAS- $1<$ AAS- 2 & AAS-1 $<$ AAS- 2 \\
\hline
\end{tabular}

TABLE 1. A statistical comparison of test results with and without SRA: where the results show no statistically significant difference, the table says "AAS-1 $\approx$ AAS-2"; where they do, the table uses a "greater-than" or "less-than" sign accordingly.

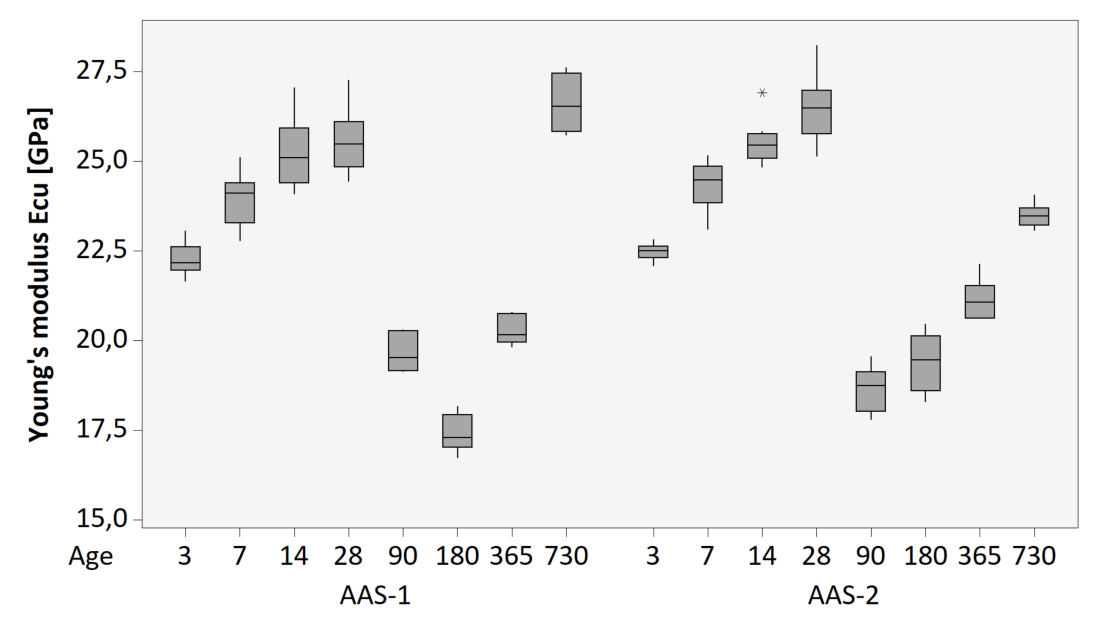

Figure 2. Box plot of the development of the Young's modulus $E_{c u}$.

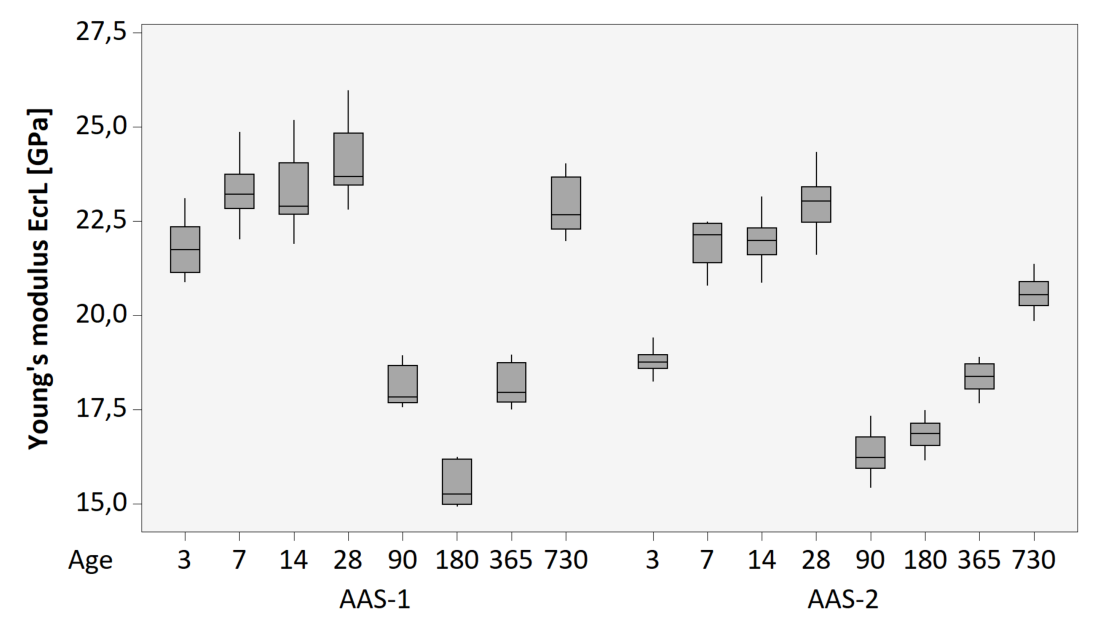

Figure 3. Box plot of the development of the Young's modulus $E_{\text {cr } L}$. 


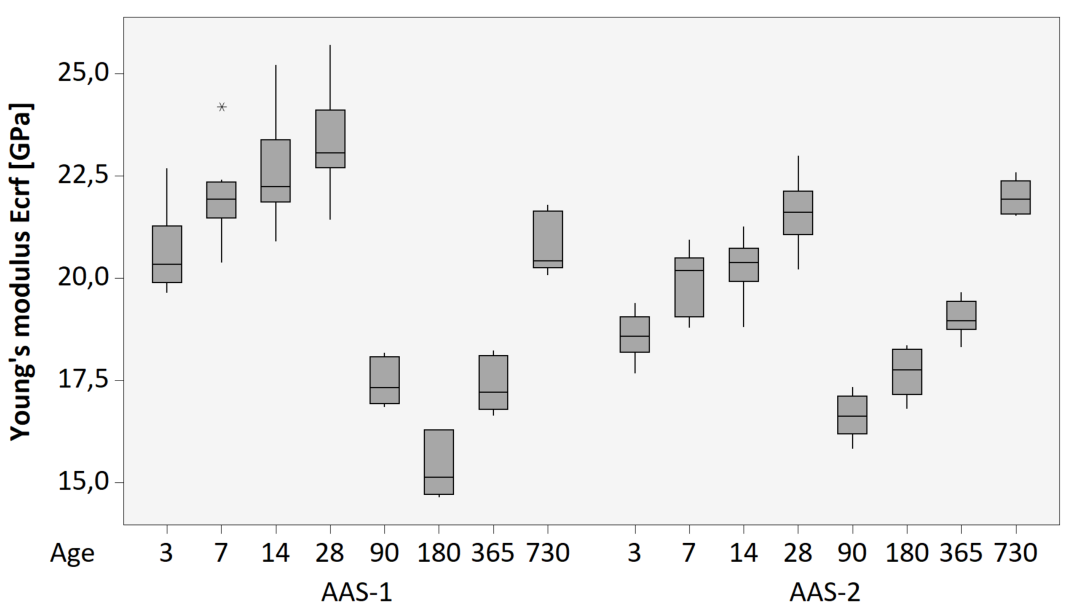

Figure 4. Box plot of the development of the Young's modulus $E_{c r f}$.

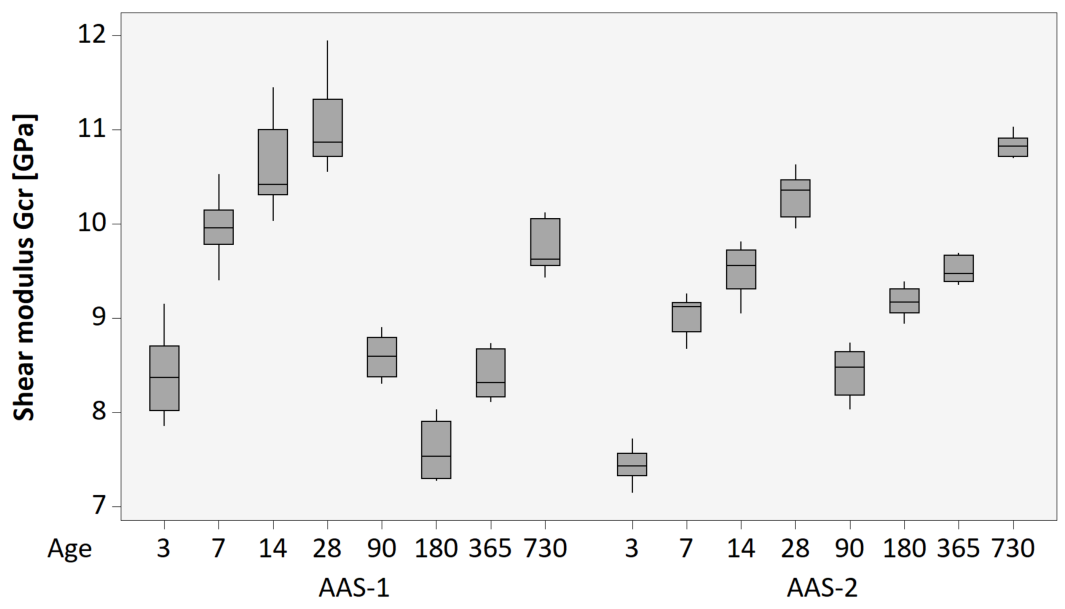

Figure 5. Box plot of the development of the Young's modulus $G_{c r}$.

higher values. No clear trend can be seen at the age of 28 and 180 days, however, at the age of 1 year the situation becomes opposite to that of 14 days. The mortar with SRA performs better at this age; with the exception of the Young's modulus measured by the resonance method (compression wave) where the two mortars do not differ with any statistical significance. At the age of 2 years it again depends which property is being observed - two properties reach significantly higher values in the AAS mortar with SRA, whereas the remaining two are higher in the mortar without SRA.

The progress of the AAS properties is very interesting, see Fig. 6 and Fig. 7 They show the progress as a percentage, with $100 \%$ being the average 28 -day value for all properties. Over the first 28 days there is a clear increase in all the properties of both mortars. Their Young's modulus reaches over $80 \%$ of its 28-day value in as few as 3 days and the shear modulus rises to more than $70 \%$. After 28 days, however, there is a fairly rapid decrease in all the properties. This is where the AAS mortar with SRA begins to differ from the AAS mortar without it.
The mortar containing SRA saw a drop in the values of the Young's modulus below the 3-day value down to $70 \%$, however, after that they began to slowly rise again $-E_{c u}$ and $E_{c r L}$ return to nearly $90 \%$ of their 28-day values in two years, and $E_{c r f}$ and $G_{c r}$ even exceed them. The decrease in all the properties of the mortar without SRA continues until the age of 180 days, with their minimum value being lower than in all the properties of the mortar containing the shrinkage-reducing admixture. After that, the mortar also begins to see an improvement; in $E_{c u}$ and $E_{c r L}$ the trend is even more pronounced than in mortar AAS-1.

\section{Conclusion}

In conclusion, an influence of the shrinkage-reducing admixture on the dynamic moduli of elasticity in AAS mortars was not statistically proved. However, the development of the Young's moduli and the shear modulus follows a very interesting trend. Over the first 28 days these values increase, followed by a marked decrease, which applies to the mortar without the shrinkage-reducing admixture as well. While the AAS mortar with the admixture begins to slowly recover 

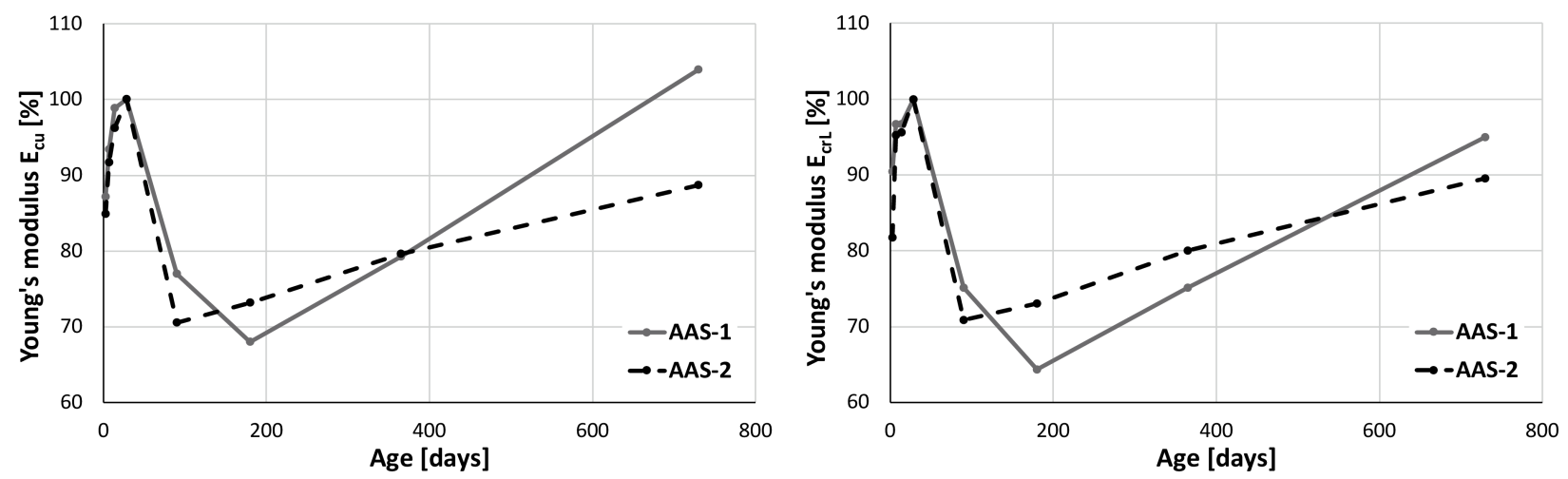

Figure 6. Development of the Young's modulus $E_{c u}$ and $E_{c r L}$, the 28-day value represents $100 \%$.
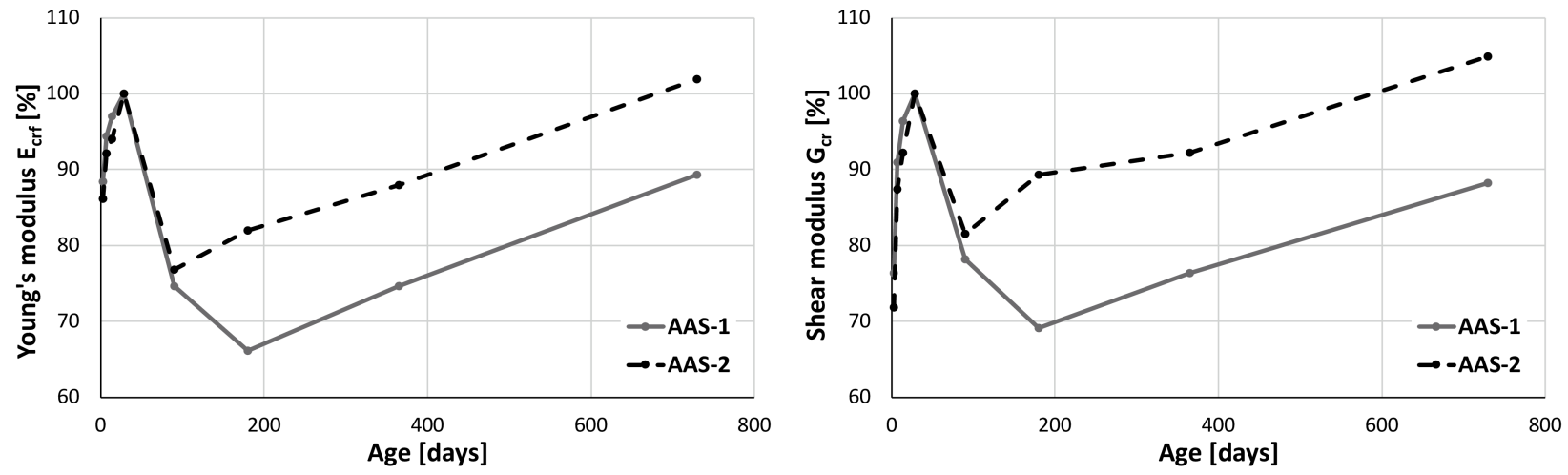

Figure 7. Development of the Young's modulus $E_{c r f}$ and the shear modulus $G_{c r}$, the 28-day value represents $100 \%$.

at the age of 90 days, the mortar without it continues to suffer a decrease until the age of 180 days when the values begin to rise again.

\section{ACKNOWLEDGEMENTS}

This paper has been written as part of the project No. GA17-14302S "Experimental analysis of the early-age volume changes in cement-based composites", supported by the GA0 - Czech Science Foundation and project No. FAST/FCH-J-18-5595 "Reduction of chemical and autogenous shrinkage of alkaline activated slag".

\section{REFERENCES}

[1] H. Ye, A. Radlińska. Shrinkage mitigation strategies in alkali-activated slag. Cement and Concrete Research 101:131-143, 2017. DOI:10.1016/j.cemconres.2017.08.025.

[2] P. Acker. Swelling, shrinkage and creep: a mechanical approach to cement hydration. Materials and Structures 37(4):237-243, 2004. DOI:10.1007/BF02480632

[3] J. Provis, J. S. J. van Deventer (eds.). Alkali Activated Materials: State-of-the-Art Report, RILEM TC 224- $A A M$, vol. 13. 2014. DOI:10.1007/978-94-007-7672-2

[4] Y. Ding, J.-G. Dai, C.-J. Shi. Mechanical properties of alkali-activated concrete: A state-of-the-art review. Construction and Building Materials 127:68-79, 2016. DOI:10.1016/j.conbuildmat.2016.09.121

[5] V. Bílek, L. Kalina, R. Novotný, et al. Some Issues of Shrinkage-Reducing Admixtures Application in
Alkali-Activated Slag Systems. Materials 9(6):462, 2016. DOI: $10.3390 / \mathrm{ma} 9060462$

[6] M. Palacios, F. Puertas. Effectiveness of mixing time on hardened properties of waterglass-activated slag pastes and mortars. ACI Materials Journal 108:73-78, 2011.

[7] B. Kucharczyková, V. Bílek Jr., D. Kocáb, O. Karel. Shrinkage of Fine-Grained Composites Based on Alkali-Activated Slag. In Non-Traditional Cement and Concrete, vol. 761 of Key Engineering Materials, pp. 7-10. Trans Tech Publications, 2018. DOI:10.4028/www.scientific.net/KEM.761.7.

[8] V. Bílek Jr., L. Kalina, J. Koplík, et al. Effect of a combination of fly ash and shrinkage-reducing additives on the properties of alkali-activated slag-based mortars. Materiali in tehnologije 50(5):813-817, 2016. DOI:10.17222/mit.2015.133.

[9] F. Collins, J. Sanjayan. Workability and mechanical properties of alkali activated slag concrete. Cement and Concrete Research 29:455-458, 1999. DOI:10.1016/S0008-8846(98)00236-1

[10] C. Shi, R. L. Day. A calorimetric study of early hydration of alkali-slag cements. Cement and Concrete Research 25(6):1333-1346, 1995. DOI:10.1016/0008-8846(95)00126-W

[11] F. Collins, J. Sanjayan. Cracking tendency of alkali-activated slag concrete subjected to restrained shrinkage. Cement and Concrete Research 30:791-798, 2000. DOI:10.1016/S0008-8846(00)00243-X 
[12] A. Neto, M. Cincotto, W. Repette. Drying and autogenous shrinkage of pastes and mortars with activated slag cement. Cement and Concrete Research 38(04):565-574, 2008.

DOI:10.1016/j.cemconres.2007.11.002.

[13] F. Collins, J. Sanjayan. Effect of pore size distribution on drying shrinking of alkali-activated slag concrete. Cement and Concrete Research 30(09):14011406, 2000. DOI:10.1016/S0008-8846(00)00327-6
[14] D. Kocáb, L. Topolář, V. Bílek Jr., et al. Experimental Analysis of the Development of Compressive Strength, Modulus of Elasticity and Acoustic Emission Parameters of Alkali-Activated Composites. In Special Concrete and Composites 2017, vol. 760 of Key Engineering Materials, pp. 266-271. Trans Tech Publications, 2018. DOI:10.4028/www.scientific.net/KEM.760.266. 